\title{
Delayed Union Fracture
}

National Cancer Institute

\section{Source}

National Cancer Institute. Delayed Union Fracture. NCI Thesaurus. Code C50529.

A bone fracture that is taking an abnormally long time to heal. 